Open Access

\title{
Are we ready to adopt mobile money in non-profit sector?
}

\author{
Fakir Md Yunus ${ }^{1 *}$, Safayet Khan', Tanjilut Tasnuba², Paroma Afsara Husain ${ }^{3}$ and Amanda Joy Misiti ${ }^{4}$
}

\author{
* Correspondence: \\ dryunus155@gmail.com; \\ yunus.fm@brac.net \\ ${ }^{1}$ BRAC Centre, BRAC Research and \\ Evaluation Division, 75 Mohakhali, \\ Dhaka 1212, Bangladesh \\ Full list of author information is \\ available at the end of the article
}

\begin{abstract}
Mobile money has grown rapidly in the past few years. It has contributed to greater financial inclusion for the poor and unbanked, bringing millions of people into a formal financial system. Despite the increased use of mobile money, little research has focused on non-profits' preparedness to mobile money adoption. This article explores staff perceptions regarding mobile money at a large Bangladeshi non-profit. The objective of the study was to understand staff and clients' opinions about using mobile money specifically focusing on reliability, efficiency, and quality. In this qualitative study, we focused on five projects and conducted a total of 11 focus group discussions and 50 in-depth interviews. We found staffs and clients were amenable to using mobile money. Most people felt that using mobile money could reduce the workload, save time and money, and make life easier for both staffs and clients. However, significant client adoption barriers exist including client literacy and numeracy levels, a lack of national identity cards and challenges obtaining them, poor mobile networks in remote areas and service fees. Some staff also expressed concerns about mobile money posing a threat to their job security. If mobile money is to realize its full potential as a financial inclusion tool for the poor and unbanked, further research is needed on mobile money adoption and implementation obstacles encountered by non-profits.
\end{abstract}

Keywords: Mobile money, Development programs, Non-profit sector, Bangladesh

\section{Background}

The term mobile money is generally understood as a service wherein mobile phones are used to access the financial services (GSMA 2010; Etim 2014). Formally, World Bank's Group named the International Finance Corporation (IFC) defines mobile money as money which can be accessed and utilized through mobile phones (Jenkins 2008). Over the last decades, the coverage of mobile phone uses increased drastically in many developing countries (Aker and Mbiti 2010; Wesolowski et al. 2012) and promoted innovation of transferring money via mobile phone (Kikulwe et al. 2014). Mobile phones are now increasingly being used for the empowerment of poor people around the world by creating a link for them to the formal financial system. This digital technology has become successful in making the market more efficient in some underdeveloped regions where there are inadequate infrastructure facilities (e.g., bad roads and slow postal services). It also helps to facilitate entrepreneurship by allowing information to move more freely and is providing a new basis for entrepreneurship

(c) The Author(s). 2016 Open Access This article is distributed under the terms of the Creative Commons Attribution 4.0 International License (http://creativecommons.org/licenses/by/4.0/), which permits unrestricted use, distribution, and reproduction in any medium, provided you give appropriate credit to the original author(s) and the source, provide a link to the Creative Commons license, and indicate if changes were made. 
and social innovation (Mansell 2012). Research suggests that the usage of an extra ten phones per 100 people in a typical developing country boosts GDP growth by 0.8 percentage points (Bhavnani et al. 2008). According to the World Bank report, around three-quarters of the world's inhabitants had access to a mobile phone in 2012. The number of mobile subscription use worldwide has grown from 1 billion in 2000 to over 6 billion now and the 5 billion of which are living in developing countries (World Bank 2012b).

As mobile phones are becoming more accessible, they are increasingly being used in many countries for financial transactions too. The share of adults with a mobile money account increased by 11 percentage points globally from 51\% in 2011 to $62 \%$ in 2014 and continues to grow which reduces the number of people who are unbanked (Kunt et al. 2015). In some countries, more people have registered for mobile money accounts than traditional bank accounts and 255 mobile money services are now live across 89 countries (GSMA 2014). However, customers' reaction on mobile money services are varied from one market to another, and the acceptance and usage by the customer does not follow the sharp pace of growth in deployments (Mukherjee 2015). Mobile money can be a much faster, less expensive, and safer way to transfer money rather than a bank or post office transfer. It creates opportunities for unbanked poor people who may be illiterate and do not have access or are intimidated by the rules and schedules of formal banks. Mobile banking is also safer than storing wealth in various forms particularly during the time of natural disasters, and some mobile money schemes in emerging markets are also being used as a form of savings vehicle (OCAIC 2010).In some cases, mobile money has helped to increase household income. A study found that the incomes of Kenyan households using mobile money have increased by $5-30 \%$ since they started mobile banking (Morawczynski and Pickens 2009). Mobile money also gives its users a way to save small amounts of money and thus develop a savings habit. Research report published by the World Bank found that mobile money users in Kenya are a third more likely to maintain savings than their peers (Mas and Radcliffe 2010). Given the fact that mobile money has substantial scope to change the life of the poor, however, limited information has been researched on the perception of using mobile money in the rural settings. Mobile financial services still do not capture the full potential of mobile money to enhance financial inclusion. As a result, it had not increased access to banking especially compared with traditional bank account designed particularly for the poor (Porteous 2007). Furthermore, little is known about the targeted client's understanding of mobile money, what is their convenience level, do they consider as safe transaction, the challenges they faced, and what they think about the ways to improve it. It is, therefore, crucial to understand beforehand the targeted clients' perception of using money, otherwise, the population will remain unbanked even the intervention of mobile money is a powerful financial tool for the community.

In Bangladesh, approximately half of the adult population is unbanked (Islam and Mamun 2011). To include this large population in the formal financial system and to meet their need, mobile-based financial services started its journey in Bangladesh 2011. The Central Bank of Bangladesh granted permission to seventeen banks initially to introduce mobile-based financial service (Bangladesh Bank 2012). Over the past three years, a mobile money industry has emerged to help meet these individuals' needs and has already reached 13 million users out of a total population of 160 million in 
Bangladesh (pi Consulting 2013). But, the registered users of these services are still very low, and most of the customers in Bangladesh use the over-the-counter (OTC) market for their transactions (CGAP blog July 2015). In addition, as Bangladesh is urbanizing rapidly, young adults working in the city send money home to their families through mobile money. In 2013, over 500 billion BDT (around 6.36 billion USD) was transacted via mobile money (pi Consulting 2013). However, the amount of payments received over mobile phone is still very low which is only $1.2 \%$ compared to other low-income countries where the average is 9.1\% (World Bank 2012a, 2012b). Bangladesh is a role model in financial inclusion for their women where $90 \%$ of borrowers are women and $35 \%$ of the women own their bank account. Given this, it is surprising that only $18 \%$ of digital finance users in Bangladesh are women. This is one of the lowest levels of mobile money usage by the women in the world (CGAP blog February 2015).

\section{Overview of the mobile money in non-profit sector}

Founded in 1972, BRAC-a non-governmental organization financial system-was set up to work with cash and paper. BRAC built a highly cost-efficient and regulated cashbased financial system through its microfinance branches across Bangladesh. Although BRAC has striven to keep up with the latest technology over the years-providing all branches with computers and internet, setting up a central database and digital data storage-the size and scale of the organization has made it challenging to adopt technology and make a transition to digitized systems. Moreover, the cash system and manual paper work which were often embedded in program activities-making it harder to adopt technology without changing the program components. For example, BRAC community health workers' or school teachers' salaries are scheduled to be disbursed in cash every month on the day they receive their training. Despite positive results in some BRAC programs and across the world, overall adoption of mobile money remained quite limited in BRAC. In 2014, BRAC obtained support for an Innovation Fund for Mobile Money for pilot projects to be done within different development programs ranging from education to health to microfinance. This initiative was launched to directly affect a significant number of BRAC's community members, extension workers, clients, and staffs. BRAC Bangladesh impacts a population of over 100 million people, and BRAC relies on the efforts of approximately 150,000 community-based teachers, health and social workers. Programs that depend heavily on cash transactions, like microfinance, incur a lot of cash-related expenses and inefficiencies. According to a recent estimation, on a typical day, a BRAC Branch Accounts Officer (BAO) spends $90 \%$ of her work hours on cash-related tasks. As an example, Fig. 1 illustrates the point through the installment and savings collection of the microfinance program in a typical daily work which may not be the same cases for other projects. In order to keep the financial transaction transparent, each of the program organizers has to go through rigorous documentation for both banking and their own institutional purposes.

In this research, we, therefore, aimed to explore the insights on preparedness and perception of different stakeholders on using mobile money technology in BRAC's different development projects. We anticipate that there are a lot of opportunities for BRAC to increase its efficiency, as well as offer better and more flexible services to clients by adopting a cashless, paper-light, digital system. However, as this type of financial 


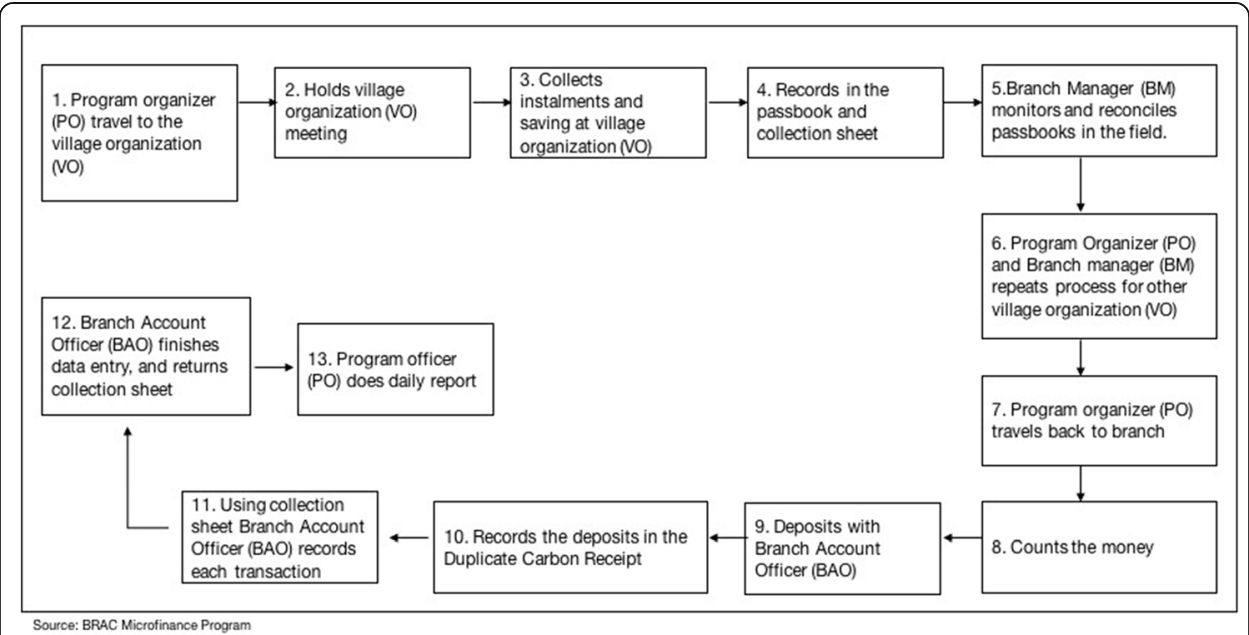

Fig. 1 Flow diagram showing the typical process that is followed to collect installments and savings from microfinance borrowers, until the transaction is registered in the management information system

services are quite new and providers are piloting this technology to replace established transaction systems in BRAC, therefore, issues related with acquiring new customers, opening mobile accounts, and helping new customers to begin transactions could arise which we have been specifically sought out in this research.

\section{Methods}

In this qualitative study, we explored the staff and clients' perceptions and opinions of using mobile money in terms of reliability, efficiency, and quality in five different BRAC projects. BRAC piloted mobile money transaction in five projects. They were (adolescent savings), ((nearly) cashless branch), (mobile micro-insurance), (Schooling, Sexual and Reproductive Health and Rights and Gender (SRHRG) and Counseling for the Children of Post-Primary Education (SSCOPE)), and (mobile payments to Community Health Workers) (Table 1). Most of these projects were introduced in rural Bangladesh, except schools which is based in Dhaka. The study was conducted in 10 sub-districts of 6 districts of Bangladesh in January, 2015.

Table 1 List of different development projects

\begin{tabular}{|c|c|c|}
\hline Projects names & Development areas & $\begin{array}{l}\text { Activities and scope of mobile money } \\
\text { transaction }\end{array}$ \\
\hline 1. Adolescent saving project (ADP) & $\begin{array}{l}\text { Adolescent Development } \\
\text { Program (ADP) }\end{array}$ & $\begin{array}{l}\text { - Individual mobile wallet savings by } \\
\text { - Gelescents } \\
\text { - General savings } \\
\text { - Monthly DPS savings } \\
\text { - Payment of honorarium for club president }\end{array}$ \\
\hline $\begin{array}{l}\text { 2. Schooling, SRHRG and Counseling } \\
\text { for the Children of Post-Primary } \\
\text { Education (SSCOPE) }\end{array}$ & Education program & $\begin{array}{l}\text { - Parents of the students will pay SSCOPE } \\
\text { school fees with an option of paying fees } \\
\text { in installments }\end{array}$ \\
\hline 3. (nearly) Cashless branch & $\begin{array}{l}\text { Integrated Development } \\
\text { Program (IDP) }\end{array}$ & $\begin{array}{l}\text { - Disbursement of loan } \\
\text { - Collection of loan installment } \\
\text { - Collection of general savings. }\end{array}$ \\
\hline 4. Mobile micro-insurance & Microfinance program & $\begin{array}{l}\text { - Client will pay through mobile money to } \\
\text { microfinance program }\end{array}$ \\
\hline $\begin{array}{l}\text { 5. Community health worker } \\
\text { mobile payments }\end{array}$ & $\begin{array}{l}\text { Health, Nutrition and } \\
\text { Population Program (HNPP) }\end{array}$ & $\begin{array}{l}\text { - Disbursement of salaries as mobile money } \\
\text { to grassroots level staff }\end{array}$ \\
\hline
\end{tabular}




\section{Study population and sampling}

Purposive sampling techniques were used for in-depth interviews. Participants were selected according to pre-determined criteria, particularly staff who worked for BRAC in a similar position for more than 3 years. The reason behind choosing them was to get their insights because they were responsible for implementing these projects at the field level. For focused group discussions (FGD), a diverse group of local people who would be involved in the mobile money transaction process were selected by BRAC locally-based field staff. They included the participants using a "snowball sampling technique," i.e., suitable people will help to get other suitable people.

Qualitative data was collected from different project administrators at the field and head office level of BRAC. We included program organizer, senior program organizer, branch manager, and branch accounts officer for this study. These staffs are the field level manager and the key person for implementing the projects at the field level. A total of 11 focus group discussion and 50 in-depth interviews were conducted in the five development projects in both rural and urban Bangladesh. We also included parents for SSCOPE and loan borrowers. Focus group discussions were undertaken in different geographical areas. Topics covered in in-depth interview included the current and proposed money transaction system, time and money spent, satisfaction, challenges, and areas to improve the mobile money transaction technology. A summary of the study participants and qualitative tools is given in Table 2.

\section{Data collection procedure}

Data was collected by five different research teams (two enumerators in each team) where each team was assigned to collect data from separate projects. We recruited 10 enumerators externally who had completed a Bachelor's degree in the social sciences. Before sending them to the field, a two-day intensive training was conducted in order to familiarize them with the questions. Questions were designed in an open-ended manner in order to promote unrestricted response. Each in-depth interview and focus group discussion took approximately 30-45 min and 45-60 min, respectively. The data obtained from the interviews was recorded by taking notes during the interviews as well as recorded them through digital audio-tape recorders after taking the consent of the participants. At the end of each working day, both teams discussed together and

Table 2 Summary of the sample and qualitative tools according to study area

\begin{tabular}{|c|c|c|c|}
\hline Projects names & No. of FGD & No. of IDI & Respondents \\
\hline 1. Adolescent saving project (ADP) & 3 & 12 & $\begin{array}{l}\text { ADP club member, and program organizer, } \\
\text { branch account officer }\end{array}$ \\
\hline $\begin{array}{l}\text { 2. Schooling, SRHRG and Counseling for } \\
\text { the Children of Post-Primary Education } \\
\text { (SSCOPE) }\end{array}$ & 3 & 9 & Parents, teachers, and program organizer \\
\hline 3. (nearly) Cashless branch & - & 7 & $\begin{array}{l}\text { Program organizer, branch account officer, } \\
\text { and beneficiaries }\end{array}$ \\
\hline 4. Mobile micro-insurance & 2 & 11 & $\begin{array}{l}\text { Microfinance borrower, program organizer, } \\
\text { branch account officer, and branch manager }\end{array}$ \\
\hline $\begin{array}{l}\text { 5. Community health worker mobile } \\
\text { payments }\end{array}$ & 3 & 11 & $\begin{array}{l}\text { Community health workers (locally called as } \\
\text { Shastho Sebika, Shastho Kormi), program } \\
\text { organizer, and Upazila manager }\end{array}$ \\
\hline
\end{tabular}


briefly synthesized the information collected throughout the day and prepared summary notes. Once the interviews were conducted, the teams returned back to Dhaka and the researchers transcribed the recordings.

Data was analyzed using the Neuman (2000) three-phase coding system. For the first phase, taped and transcribed data was scanned by each researcher which led to a certain degree of familiarization with the factors considered and to locate the themes. Each researcher looked at the range, content, and diversity of the raw data. Secondly, priori codes, inductive codes, and sub codes were generated, identified, and defined in a broader group. Definition includes code abbreviations, color coding, full description, when to use, when not to use, and examples from transcripts. At the end, each researcher reread the sorted data and finalized the final theme. The transcripts were checked by other researchers to increase the validity of the data.

\section{Results}

Our analysis was intended to explore a wide-ranging story of using mobile money in the rural Bangladesh. It was, therefore, important to know at the first instance that the current practice of saving money and alongside how they understand about the mobile money, where they heard about it and its usefulness. In order to understand more insights, we further analyzed whether mobile money transaction service is convenient for them, the challenges they faced and how it can be improved. Hence, our analysis identified and uncovered six main themes such as understanding the mobile money transfer, its convenience, time spent, money expenses, challenges, and ways to improve it. Details are presented in Table 3.

\section{What is a mobile money transaction system?}

Most participants were comfortable talking about mobile money although a few of the participants mentioned that they usually save money physically in a container. Participants understood mobile money to be transferring money through a mobile SIM card number

Table 3 Factors for using mobile money

\begin{tabular}{|c|c|c|}
\hline Projects names & Development areas & Factors \\
\hline 1. Adolescent saving project (ADP) & $\begin{array}{l}\text { Adolescent Development } \\
\text { Program (ADP) }\end{array}$ & $\begin{array}{l}\text { Safe, easily accessible, less work, } \\
\text { confidentiality, detail transaction } \\
\text { history, easy transaction, less hassle }\end{array}$ \\
\hline $\begin{array}{l}\text { 2. Schooling, SRHRG and Counseling } \\
\text { for the Children of Post-Primary } \\
\text { Education (SSCOPE) }\end{array}$ & Education program & $\begin{array}{l}\text { Easy, safe and secure, less pressure, } \\
\text { better system, saves time, ensure } \\
\text { timely transaction and maintain } \\
\text { transparency, costly in case of } \\
\text { frequent transaction }\end{array}$ \\
\hline 3. (nearly) Cashless branch & $\begin{array}{l}\text { Integrated Development } \\
\text { Program (IDP) }\end{array}$ & $\begin{array}{l}\text { Time saving, need education, accuracy, } \\
\text { less workload, transparent }\end{array}$ \\
\hline 4. Mobile micro-insurance & Microfinance program & $\begin{array}{l}\text { Time saving and less physical labor, } \\
\text { awareness, reduce chance of errors, } \\
\text { reduce workload, transparency, } \\
\text { convenience, safe }\end{array}$ \\
\hline $\begin{array}{l}\text { 5. Community health worker mobile } \\
\text { payments }\end{array}$ & $\begin{array}{l}\text { Health, Nutrition and Population } \\
\text { Program (HNPP) }\end{array}$ & $\begin{array}{l}\text { Transparent transaction, time saving, } \\
\text { less workforce, less travel, convenience, } \\
\text { do not need education and awareness, } \\
\text { need time to convince client, less } \\
\text { physical work }\end{array}$ \\
\hline
\end{tabular}


from one person to another person.In regard to the usefulness of the mobile money, one of the participants stated:

"Saving money through clay or plastic container is an obsolete approach......it is not suitable in current days!" (Micro-insurance IDI 3)

Some of them had heard about the option of mobile money transaction through "bKash" on television advertisements and a few heard about it from word-of-mouth.

"bKash could be a gateway to the rural people of Bangladesh- those who are not included in the formal banking system............. and they can potentially get the benefits of banking". (ADP IDI 10)

\section{Convenience of using mobile money}

Based on their previous personal experience using mobile money, most of the respondents believed that it could be a very beneficial initiative. They considered saving money through mud- or plastic-made banks as an outdated method. They mentioned safe transactions and accessibility as the main benefits of using mobile money.

".........also it is not possible to take the clay banks wherever we go! and also it could be stolen!" (IED IDI 3)

"Mobile money transaction would be very helpful. It will be safe and could be accessible anytime we want...... which makes our life easier". (ADP IDI 6)

"Three benefits we can get from mobile money...less labor in cash handling, doesn't take much time, and there is no risk for handling and transporting cash". (Micro-insurance IDI 7)

BRAC staffs were overall quite optimistic about the potential of mobile money. The majority of the respondents assumed that introducing mobile money could reduce their workload. People working in the accounts department in rural areas spent a great deal of time handling cash every day as a part of their daily activities. In regard to the operational activity related to cash money transactions existing in the current system, BRAC staff found it to be a very rigid official procedure and it is sometimes frustrating. However, a few mentioned that at the beginning of any new initiative, there was always extra work. Some said that they thought this initiative would lead to less paperwork. BRAC staffs and clients highlighted that mobile money could be the appropriate method for dealing with cash where there is limited or no formal banking. They added, in some remote areas such as "char"-low-lying flood and erosion-prone areas in or adjacent to major rivers (Hodson 2006) where there is no space (any formal banking system) to save and/or transact money. With regard to disasters, they believed they have a good network in disaster-prone areas with local leaders and businessmen. After any disaster, they could list the vulnerable people who were negatively affected and could send money to them quickly. The majority of the staff interviewed believed mobile money transactions could save time and money for BRAC. 
"I am always under extreme pressure at work! It is very difficult to work with cash from dawn to dusk..." (IDP IDI 5)

"We have to maintain several logs ... if there is any error in one logbook, then we have to re-check each and every logbook" - (ADP IDI 3)

"I have to maintain many documents at a time, therefore the chance of error is high" (Micro-insurance IDI 4)

“...............new system could reduce workload". (HNPP IDI 9)

\section{Time spent in mobile money}

The majority of BRAC staff think that mobile money transactions could save time and thereby improve the overall system. Most accounts officers spent time traveling and waiting in lines in the nearby bank on a daily basis to complete their work. In addition, the banks remain closed on Friday and Saturday, so whenever money is needed, the staffs have to wait until weekdays.

"Maintaining an account usually takes time... difficult to calculate, people do not take salary at a time.......minimum takes 30-40 minutes. However, I can imagine mobile money takes 2-3 minutes." (SSCOPE IDI 2)

"what do I do?.......should I wait in line at the bank for hours or do my daily job at office? ......sometimes it takes almost half of my working day!" (IDP IDI 6)

"Now we don't need to go to bank and wait for a couple of hours" (SSCOPE IDI 4)

"Now it may take 10 minutes instead of 30-40minutes" (IDP IDI 3)

\section{Expense of mobile money}

Respondents had mixed opinions about using mobile transactions. Some of them think it could potentially reduce transportation costs. Each staff member needs to incur expenses to visit a bank. Staffs also think that they would not require to spend the transportation allowance on the salary day and/or during their field visit for account purposes. However, a few of them mentioned that they considered bKash service charges should be eliminated. They mentioned that if mobile money costs increased, then they would support the traditional cash system. They seemed a bit confused about the mobile money service charge rate. Some of them stated that the charge rate should be reduced. Many BRAC staffs felt the same way about the charge and assumed that clients may not want to pay the fee to withdraw cash money and therefore they might not benefit from this new system, and they recommended that the office should not charge clients the cash withdrawal fee.

"This have both pros and cons......it charges money to cash-in and -out and becomes expensive...." (SSCOPE IDI 3)

"if you want to launch mobile money, we have no objection. But we will not spend a single penny for this purpose-we are poor" (Micro-insurance FGD 2) 


\section{Challenges of mobile money}

Some of the BRAC staffs were concerned about using mobile money at the community level, and they mentioned educating people about mobile money, specifically the cashout fee (1.85\%) and the minimum cash-in amount (50 BDT/USD 0.64) which could be the main challenges of introducing mobile money at the community level. They think that understanding mobile function is crucial-particularly the short message service (SMS) and the unstructured supplementary service data (USSD) menu of all mobile money provider services appeared in English. In rural Bangladesh, people have very limited or no education. It is difficult for them to read the SMS and operate the USSD menu in the mobile phone. They added that clients who cannot read and have no idea of using a mobile phone should be educated (for those who do not have mobile phone), the basics of how they work, and also the importance of remembering their PIN (bKash provided security code) number. A few of the staffs were concerned about accidentally sending money to a wrong number, and a few of them said that not having a national ID card and a poor network connection could be big challenges. Apart from this, a few staff members thought that introducing mobile money in the program administration could reduce the demand and/or need for employees; hence, they were worried about their job security.

"Remembering PIN number is a challenge". (ADP IDI 11)

"........... getting trust from the community people is crucially important” (ADP IDI 1)

"If mobile money is included in this (operational) process, there will not be as many staff in this office as we are now. I consider this as a problem" (Micro-insurance IDI 7)

"This will increase efficiency in service delivery but also increases unemployment" (Micro-insurance IDI 5)

Most of the respondents agree that the usage levels of bKash vary in different locations. They added that bKash agents sometimes ask for extra money. BRAC staffs argue that if a program organizer goes to a participant's home, then it would be easier to get the money owned, but if they do not go, they might not get the money in time-which creates problems.

\section{Areas to improve for community adoption}

Although there are many challenges, the majority of the people think that these could be resolved. They highlighted that community people need to be trained on how to use new technologies. They believe posters, flipcharts, and pocket cards help to increase their understanding. In order to obtain the community's trust, they believe BRAC staffs should counsel them in-person. A few argued that it would take time to adopt the system as this is new, but over the period of time, despite its challenges, it will go well. They were concerned that regular follow-up will be needed for clients who have no mobile phone or who have a newly created account.

"Parents didn't take this initiative positively.........they consider it to be an extra pain, but once they understood it, they appreciated it..." (SSCOPE IDI 9) 
"BRAC should reduce the charge for their beneficiaries." (Micro-insurance IDI 11)

"We don't expect people to change over time" (Micro-insurance IDI 7)

\section{Discussion}

Although challenges exist, the study shows there is an overall positive impression towards using mobile money by BRAC staffs and its clients. Previous studies on the use of mobile money by the rural poor reported the positive perception towards the adoption of this new banking system (Kikulwe et al. 2014). This study, however, suggests that implementation of this new innovation might have some positive and negative consequences. We conducted a qualitative research to understand the perception of introducing mobile money in the development sector. We explored different staff and clients' perception of using mobile money in terms of reliability and efficiency in the five different BRAC programs.

Most of the respondents were aware of mobile money, understood how it worked, and had a mobile account. They first came to know about mobile money through advertisements by different service providers such as bKash, DBBL mobile banking, and others. Some of them came to know about this from other people as word of mouth. Safe transactions were the main benefit that they mentioned. This was the primary motive of Bangladesh Bank that safe transaction and cover larger number of population (Bangladesh Bank, 2012). Some described mobile money as a medium of trouble-free transaction and the ease of access. Some of the respondents think mobile money is a better system because it saves time during their daily work. Study on M-PESA-the Kenyan mobile money service-mentioned that fast, cheaper, safer, and simplicity around the usefulness of the provider's service was the key of success as the mobile money service application runs from the default phone menu (Mas and Morawczynski 2009; Jack and Suri 2011; Maurer 2012). In another study, the customers said that this type of payment service would provide them freedom of time and space. However, perceived usefulness was found to have no effects on the adoption of mobile payment services (Denovan 2012). In our study, we found that introducing mobile money would reduce the respondent's workload as there will eventually be no paper work. As this was a new initiative, some people mentioned that there will be some extra work at the beginning. On the contrary, some people expressed concern that staffs might become redundant and lose their jobs because of this new system. Mobile money can be beneficial where there is little or no formal banking. In "char"- silt sedimentation creates a new land (Banu 2002) and disaster-prone areas, mobile money can be useful to save or transact money as well as to buy relief goods quickly. One of the accounts officers said that banks remain closed for 2 days every week and queuing for withdrawing money can be time consuming. This system would further reduce the organization's expenses as it would not need to reimburse its field-based employees for their transportation.

All the mobile money service providers in Bangladesh charge a fee for their services, and this is considered by some as a problem. The charging fee for providing service is not only happening in Bangladesh, other similar service providers such as M-PESA-one the successful mobile money service providers based in Kenya-also charged a fee during the withdrawal of money (Jack and Suri 2011). Some of the respondents were confused about mobile money charge rates and stated that this varies geographically. In some instances, 
agents ask for extra charge. One of the potential solutions in regard to this issue is that regular (at least monthly) in-person/on-site visit with the agents by the mobile money service provider. Taking example from the M-PESA, the service provider is in full control even to their agents as it eventually helped to built good relation and gain trust from their agents and as well as the consumers (Mas and Morawczynski 2009; Ngugu and Pelowski 2010). We noted that the service charges could be the main barrier to the use of mobile money. Some respondents pointed out that they would support the traditional cash system, if they find that mobile money costs them extra money. High transaction cost was also one of the barriers in adopting mobile money in Tanzania (Chogo and Sedoyeka 2015). Several East African countries including Kenya levies tax on all kinds of mobile money transfer systems and have experienced a downward trend in the value of mobile payment (World Bank 2012b).

Many clients may not understand how mobile money works and experience challenges, like remembering their passwords. Poor user support which includes unfriendly user interface and lack of procedure training were some of the factors which affected mobile money adoption in Tanzania (Chogo and Sedoyeka 2015). Moreover, not having a national ID card and access to mobile networks could be big challenges for opening up a mobile money account and using the services. Thus, clients' education levels are also important because they need to understand the short message, which is in English, received from mobile money service provider. Highlighting this key point, other study, furthermore, strongly suggested that mobile money service provider should use nontext designs over text-based designs. Besides, they found that rich multimedia UI is much faster and required minimum assistance to complete the transaction (Medhi et al. 2009). It is also equally important for the client to know the benefits and challenges of the mobile money service system. Regular follow-up in-person is necessary for those who have not used a mobile phone before or who have recently opened a mobile banking account.

Although there are enormous potentials of using mobile money particularly for the underprivileged and unbanked population in the low-income countries, but there is limited data on its adoptions. Even more limited data on perception of using mobile money as an alternative money transaction system than the traditional banking system. To the best of our knowledge, we did not find any other studies that compiled and explored the perception of using mobile money from both the service provider and the beneficiaries in the non-profit sector in Bangladesh. This qualitative understanding of using mobile money would help the mobile money service providers/ companies/institutions, policy makers, entrepreneurs, researchers to consider field level implementers and targeted beneficiaries' thoughts during making their business/policy plan and/or technological advancement. The findings of this study will also shed light on the issues that need to be considered while developing the marketing strategies. Besides, policy makers and donors may push the implementers towards community engagement as this study highlights it as an important tool to convince the benefices in order to build a sense of trust between the institutions and the clients. One of the limitations of this study is that the findings may not be generalized to other settings as these findings are based on the respondents own sets of meaning. However, this study design is powerful enough to describe the complex phenomena and identify the contextual and setting factors of use of mobile money in rural Bangladesh. Besides, 
interpretation of the results should be done with caution as it may not be appropriate to make any quantitative predictions.

\section{Conclusions}

In general, both the service provider and the beneficiaries were receptive to using mobile money in the non-profit sector. There is a consensus that mobile money transactions have the potential to make people's lives easier as compared with the current cash transfer system. It could save time and secure their money. Upgrading the current cash-based system to the mobile money system would be time worthy given that the challenges have taken into consideration.

\section{Acknowledgements}

We would also like to thank Mr. Andrew Jenkins and Ms. Maria A. May for reviewing the manuscript and valuable feedback.

\section{Funding}

This research was funded as part of a larger project at BRAC focused on innovation with digital financial services, supported by the Bill \& Melinda Gates Foundation.

\section{Competing interests}

The authors declare that they have no competing interests.

\section{Authors' contributions}

FMY, MSK, PAH, TT, and AJM conceived the study and designed the study. FMY and MSK conducted the analysis. FMY, MSK, PAH, TT, and AJM wrote the manuscript. All authors read and approved the final manuscript.

\section{Ethics approval and consent to participate}

The process, risk, and benefits of participating in the study were comprehensively explained to all the participants, and interviews were recorded anonymously, with confidentiality maintained. It was explained to the participants that their participation was completely voluntary and could be withdrawn at any point. Since they provided verbal consent, the interviewer put a tick mark in the "I Agree" box on the form in the presence of a witness. The study protocol and consent procedure was approved by the BRAC Research and Evaluation Division.

\section{Author details}

${ }^{1}$ BRAC Centre, BRAC Research and Evaluation Division, 75 Mohakhali, Dhaka 1212, Bangladesh. ${ }^{2}$ BRAC Centre, Social Innovation Lab, 75 Mohakhali, Dhaka 1212, Bangladesh. ${ }^{3}$ BRAC Microfinance Programme, 75 Mohakhali, Dhaka 1212, Bangladesh. ${ }^{4}$ The New York University Robert F. Wagner Graduate School of Public Service, 295 Lafayette Street, New York, NY 10012-9604, USA.

Received: 17 June 2016 Accepted: 28 November 2016

Published online: 05 December 2016

\section{References}

Aker, J. C., \& Mbiti, I. M. (2010). Mobile phones and economic development in Africa. Journal of Economic Perspectives, 24, 207-32. doi:10.1257/jep.24.3.207.

Bangladesh Bank (2012) Mobile financial services in Bangladesh: an overview of market development, Bangladesh Bank Policy Paper: 1-28

Banu, D. (2002). BRAC char development and settlement project 2000-2004. Mid-term evaluation report, BRAC Research and Evaluation Division

Bhavnani, A., Chiu, R. W.-W., Janakiram, S., Silarszky, P., \& Bhatia, D. (2008). The role of mobile phones in sustainable rural poverty reduction. Working Paper 44678. Washington DC: World Bank.

CGAP blog (February 3, 2015) Digital finance in Bangladesh: where are all the women?: Leesa Shrader, Consultant of Branchless Banking. http://www.cgap.org/blog/digital-finance-bangladesh-where-are-all-women. Accessed 30 May 2016.

CGAP blog (July 9, 2015) Mobile money in Bangladesh: still a long way to go: Nathaniel Kretchun, Senior Associate Director, InterMedia. http://www.cgap.org/blog/mobile-money-bangladesh-still-long-way-go. Accessed 30 May 2016.

Chogo, P. J., \& Sedoyeka, E. (2015). Exploring factors affecting mobile money adoption in Tanzania. International Journal of Computing and ICT Research, 8(2), 53-64.

Denovan, K. (2012). Mobile money for financial inclusion in information and communication for development 2012: maximizing mobile. Washington, DC: World Bank.

Etim, A. S. (2014). Mobile banking and mobile money adoption for financial inclusion. Research in Business and Economics Journal, 9, 1-13.

GSMA. (2010). Mobile money definitions (Mobile money for the unbanked). London: GSMA.

GSMA. (2014). State of the Industry (Mobile money for the unbanked). London: GSMA.

Hodson, R. (2006). The chars livelihood programme: The story and strategy so far. Dhaka: BRAC Research and Evaluation Division.

Islam, E., and Mamun, S.A.M. (2011). Financial inclusion: the role of Bangladesh Bank. Working Paper Series: WP1101.

Dhaka: Research Department, Bangladesh Bank.

Jack, W., \& Suri, T. (2011). Mobile money: the economics of M-PESA. NBER Working Paper No. 16721. 
Jenkins, B. (2008). Developing mobile money ecosystems. USA: IFC, World Bank and Harvard Kennedy School of Government.

Kikulwe, E. M., Fischer, E., \& Qaim, M. (2014). Mobile money, smallholder farmers, and household welfare in Kenya. PLoS One, 9(10), e109804

Kunt, A.D., Klapper, L.,Singer, D., \& Oudheusden, P.V. (2015). The global findex database 2014: Measuring financial inclusion around the world. World Bank Policy Research Working Ppaer, 7255

Mansell, R. (2012). Mobile phones: challenges of capability building. Georgetown Journal of International Affairs, 13 (2). ISSN 1526-0054.

Mas, I., \& Morawczynski, O. (2009). Designing mobile money services: lessons from M-PESA. Innovations, 4(2), 77-91. Mas, I., \& Radcliffe, D. (2010). Mobile payments go viral: M-PESA in Kenya. Washington, DC: World Bank.

Maurer, B. (2012). Mobile money: communication, consumption and change in the payments space. The Journal of Development Studies, 48(5), 589-604.

Medhi, I., Gautama, S. N. N., \& Toyama, K. (2009). A comparison of mobile money-transfer Uls for non-literate and semiliterate users. Proc. 27th Int. Conf. Hum. factors Comput. Syst. - CHI 09 [Internet]. New York, New York, USA: ACM Press. [cited 2016 Nov 3]. p. 1741. Available from: http://dl.acm.org/citation.cfm?doid=1518701.1518970.

Morawczynski, O., \& Pickens, M. (2009). Poor people using mobile financial services: observations on customer usage and impact from M-PESA. Washington, DC: CGAP Brief. World Bank.

Mukherjee, J. (2015). Mobile money adoption in India: evidence from early adopters of technology. Vikashan XIMB Journal of Management, 12(II), 95-118.

Neuman, W. L. (2000). Social research method. University of Wisconsin at Whitewater

Ngugu, B., \& Pelowski, M. (2010). M-PESA: a case study of the critical early adopters' role in the rapid adoption of mobile money banking in Kenya. EJISDC, 43(3), 1-16.

OCAIC. (2010). Mobile commerce: new experiences, emerging consumer issues. The Consumer Trends Update, Canada pi Consulting. (2013). Mobile financial services: consumer insights study. pi Strategy Consulting, Dhaka.

Porteous, David. (2007). Just how transformational is M-banking? FinMark Trust

Wesolowski, A., Eagle, N., Noor, A. M., Snow, R. W., \& Buckee, C. (2012). Heterogeneous mobile phone ownership and usage patterns in Kenya. PLOS ONE, 7(4), e35319. doi:10.1371/journal.pone.0035319.

World Bank. (2012a). The little data book on financial inclusion. Washington, DC: World Bank

World Bank. (2012b). Information and communication for development 2012: maximizing mobile.Washington, DC: World Bank. doi:10.1596/978-0-8213-8991-1; website: http://www.worldbank.org/ict/IC4D2012. Accessed 29 Oct 2016.

\section{Submit your manuscript to a SpringerOpen ${ }^{\circ}$ journal and benefit from:}

- Convenient online submission

- Rigorous peer review

- Immediate publication on acceptance

- Open access: articles freely available online

- High visibility within the field

- Retaining the copyright to your article 